\title{
Journal of the National Cancer Institute
}

National Cancer Institute

\section{Source}

National Cancer Institute. Journal of the National Cancer Institute. NCI Thesaurus. Code C19209.

The Journal of the National Cancer Institute publishes manuscripts that describe new findings of particular significance in any area relating to cancer, as well as associated news items, reviews, and opinion pieces. The Journal endeavors to appeal to a broad, multidisciplinary audience. Contents include: Peer-reviewed reports on major oncology studies from around the world; Editorials and commentary by leading experts on key articles and current controversies in cancer; The latest news from the oncology community, book reviews, and conference and position announcements. (from JNCI Information for Authors) 